University of Nebraska - Lincoln

DigitalCommons@University of Nebraska - Lincoln

Agronomy \& Horticulture -- Faculty Publications

Agronomy and Horticulture Department

$1-1982$

\title{
Influence of Radiation Level on Apparent Hydrocyanic Acid Potential of Sorghum Seedlings
}

\author{
Francis A. Haskins \\ University of Nebraska-Lincoln, fhaskins@neb.rr.com \\ Herman J. Gorz \\ United States Department of Agriculture \\ R. B. Clark \\ University of Nebraska-Lincoln
}

Follow this and additional works at: https://digitalcommons.unl.edu/agronomyfacpub

Part of the Plant Sciences Commons

Haskins, Francis A.; Gorz, Herman J.; and Clark, R. B., "Influence of Radiation Level on Apparent Hydrocyanic Acid Potential of Sorghum Seedlings" (1982). Agronomy \& Horticulture -- Faculty Publications. 238.

https://digitalcommons.unl.edu/agronomyfacpub/238

This Article is brought to you for free and open access by the Agronomy and Horticulture Department at DigitalCommons@University of Nebraska - Lincoln. It has been accepted for inclusion in Agronomy \& Horticulture -Faculty Publications by an authorized administrator of DigitalCommons@University of Nebraska - Lincoln. 


\title{
Influence of Radiation Level on Apparent Hydrocyanic Acid Potential of Sorghum Seedlings ${ }^{1}$
}

\author{
F. A. Haskins, H. J. Gorz, and R. B. Glark ${ }^{2}$
}

\begin{abstract}
The hydrocyanic acid potential (HCN-p) of forage sorghum [Sorghum bicolor (L.) Moench] and sudangrass [S. sudanense (Piper) Stapf] seedlings may be estimated by a spectrophotometric procedure that is simple and rapid. As assayed by this procedure, seedlings of a number of lines appeared to have increased HCN-p when grown under increased levels of radiation. In investigations of this apparent increase, 7-day seedlings of a number of forage sorghum and sudangrass lines were grown under photosynthetically active radiation levels of about $180 \mu \mathrm{E} \cdot \mathrm{m}^{-2} \cdot \sec ^{-1}(\mathrm{PAR}-1)$ or $400 \mu \mathrm{E} \cdot \mathrm{m}^{-2} \cdot \mathrm{sec}^{-1}($ PAR-2). Extracts of first leaves were diluted in $0.1 \mathrm{~N} \mathrm{NaOH}$ and scanned from 400 to $250 \mathrm{~nm}$. These scans revealed the occurrence, especially in leaf extracts from lowHCN-p seedlings grown under PAR-2, of substances that interfered with the $330 \mathrm{~nm}$ absorption maximum of $p$-hydroxybenzaldehyde $(p-\mathrm{HB})$, on which the spectrophotometric assay is based. Fractionation of the aqueous extracts with ether effectively separated $p$-HB from the interfering compounds. Also, $p-\mathrm{HB}$ added to the aqueous extracts was effectively recovered in the ether phase following fractionation. It was concluded that seedlings to be assayed by the spectrophotometric method should be grown under radiation levels no higher than $200 \mu \mathrm{E} \cdot \mathrm{m}^{-2} \cdot \mathrm{sec}^{-1}$, and it was recommended that spectra be scanned and/or ether extraction be used for any entries assaying less than $250 \mathrm{ppm} \mathrm{HCN-p} \mathrm{by} \mathrm{this}$ method.
\end{abstract}

Additional index words: Dhurrin, Prussic acid, Cyanide, Sudangrass, Forage sorghum, Sorghum sudanense (Piper) Stapf, Sorghum bicolor (L.) Moench.

A simple and rapid spectrophotometric procedure for assaying the hydrocyanic acid potential (HCN-p) of Sorghum seedlings was described in a previous report from this laboratory (4). The procedure, which was based in part on earlier studies by Akazawa et al. (1), consists of excising and weighing first leaves of the seedlings, autoclaving the leaves in water, diluting the extracts in $0.1 \mathrm{~N}$ $\mathrm{NaOH}$, and reading the absorbance of the resulting solutions at $330 \mathrm{~nm}$. The procedure is effective because dhurrin [ $(S)$ - $p$-hydroxymandelonitrile $\beta$-D-glucopyranoside], the cyanogenic glucoside of Sorghum, is readily extracted and hydrolyzed when the leaf tissure is autoclaved in water; HCN, glucose, and $p$-hydroxybenzaldehyde ( $p$ $\mathrm{HB}$ ) in equimolar amounts are the products of this hydrolysis (1); and $p-\mathrm{HB}$ in alkaline solution has a strong absorption maximum at $330 \mathrm{~nm}$. When Sorghum seedlings were grown as described (4), high-HCN-p lines yielded extracts whose spectra closely resembled the spectrum of $p-\mathrm{HB}$, and the $330 \mathrm{~nm}$ maximum characteristic of $p-\mathrm{HB}$ also was readily apparent in extracts of low-HCN-p lines (5). The ranking of genotypes for HCN-p as determined by this spectrophotometric procedure agreed well with rankings based on other assay methods (4).

We have used the spectrophotometric assay in various studies of Sorghum HCN-p (2, 5, and unpublished). During these investigations we observed that some lines, when grown under relatively high levels of photosynthetically active radiation (PAR), appeared to have somewhat higher HCN-p than when they were grown under relatively low PAR levels. This paper presents the results of a series of experiments designed to determine whether this apparent increase was real or whether it might have been an artifact of the procedures used in growing the seedlings and assaying HCN-p.

\section{MATERIALS AND METHODS}

Seedlings of forage sorghum [Sorghum bicolor (L.) Moench] and sudangrass [S. sudanense (Piper) Stapf] were grown in plastic trays in a mixture of soil, sand, vermiculite, perlite, and peat moss

${ }^{1}$ Contribution from AR-SEA-USDA, and the Dep. of Agronomy, Nebraska Agric. Exp. Stn., Lincoln. Published as Paper No. 6161. Journal Series, Nebraska Agric. Exp. Stn. Received 20 Feb., 1981.

"George Holmes professor of agronomy; supervisory research geneticist, AR-SEA-USDA and professor of agronomy; and research chemist, AR-SEA-USDA and professor of agromony; Univ of Nebraska, Lincoln, NE 68583 
(approximately $4: 1: 1: 1: 1$ by volume) essentially as previously described (4). This mixture was saturated by subirrigation with Hoagland's Solution No. 1 (6) immediately before seeds were planted, and with water 1 or 2 days before seedlings were to be sampled. The seedlings were grown in chambers at $27 \pm 1 \mathrm{C}$ under continuous cool white fluorescent light. All seedlings were started under a light level of about $180 \mu \mathrm{E} \cdot \mathrm{m}^{-2} \cdot \sec ^{-1}(\mathrm{PAR}-1)$. When seedlings were about $1 \mathrm{~cm}$ tall ( 3 or 4 days after planting), half of the trays were moved to a chamber where the seedlings were exposed to about $400 \mu \mathrm{E} \cdot \mathrm{m}^{-2} \cdot \mathrm{sec}^{-1}(\mathrm{PAR}-2)$; the remaining trays were left at PAR-1.

Seedlings were sampled for extraction at 7 days after planting. In most cases two samples, each consisting of the blades of five first leaves, were taken for each entry within each treatment. Weighed samples were extracted with water (usually 10 $\mathrm{ml}$ ) in the autoclave, and extracts were diluted in $0.1 \mathrm{~N} \mathrm{NaOH}$ for readings of absorbance at $330 \mathrm{~nm}$ (4). Seedlings also were classified for green or red stem color at the time of sampling. Stem color actually refers to the color of the coleoptile and the sheath of the first seedling leaf; no stem tissue was outwardly visible at this time. Unless otherwise specified, stem color applies to 7-day seedlings grown under PAR-1.

The foregoing procedures for growing and sampling scedlings were followed in all experiments included in this study except for one experiment in which tillers from field-grown plants were used. The field-grown plants were produced from seedlings started in the growth chamber and then transplanted, first to the greenhouse and later to the field, in the spring of 1979 . Tillers approximately $20 \mathrm{~cm}$ tall were sampled; the sample in each case consisted of the oldest leaf without a collar. Procedurcs for preparing and examining extracts of tiller leaves were like those used for seedling leaves.

For spectral scanning and ether fractionation, composite extracts were made by combining equal volumes of the aqueous extracts within entries and treatments. Each composite extract was diluted in $0.1 \mathrm{~N} \mathrm{NaOH}$, and the spectrum of the resulting solution was scanned immediately from 400 to $250 \mathrm{~nm}$. In some experiments, $10-\mathrm{ml}$ portions of the composite extracts were extracted with three successive 5 -ml portions of diethyl ether, and the combined ether phases were cvaporated to near dryness in a $50 \mathrm{C}$ water bath and reconstituted with water. Aqueous phases and reconstituted ether phases were diluted with $0.1 \mathrm{~N}$ $\mathrm{NaOH}$ for spectral scanning between 400 and $250 \mathrm{mn}$. A Beckman Model DB-G spectrophotometer and a Beckman Model 1005 recorder were used for scanning and plotting of spectra. ${ }^{3}$

\section{RESULTS AND DISCUSSION}

Experiment 1. Seedlings of 21 experimental sudangrass lines representing a range in HCN-p from about 200 to 700 ppm (under PAR-1) were grown under PAR-1 and PAR-2. As shown in Table 1, 12 of these lines had red stems under PAR-1; the remaining nine had green stems. At 7 days of age, seedlings exposed to PAR-2 appeared to be higher in HCN-p than seedlings grown under PAR1; 11 of the 12 red-stemmed entries and 8 of the 9 greenstemmed entries had higher HCN-p levels under PAR-2 than under PAR-1.

The most obvious visual effect of PAR-2 was its influence on stem color. Each of the 12 entries with red stems under PAR-1 developed considerably more red pigmentation under PAR-2, and 8 of the 9 entries that were

Mention of a trademark or proprietary product does not constitute a guarantee or warranty of the product by USDA or the Univ. of Nebraska, and docs not imply its approval to the exclusion of other products that may also be suitable.
Table 1. Apparent HCN-p and $A_{980} / A_{9 s 0}$ ratios for 21 sudangrass lines grown under two levels of radiation (Exp. 1). Duplicate five-leaf samples were assayed for each line.

\begin{tabular}{|c|c|c|c|c|c|c|}
\hline \multirow{2}{*}{$\begin{array}{c}\text { Stem } \\
\text { color } \\
\text { (PAR 1) }\end{array}$} & \multirow{2}{*}{$\begin{array}{l}\text { No. } \\
\text { of } \\
\text { lines }\end{array}$} & \multirow{2}{*}{$\begin{array}{c}\text { Statis- } \\
\text { tic }\end{array}$} & \multicolumn{2}{|c|}{$\begin{array}{c}\text { Apparent } \\
\text { HCN-p (ppm) }\end{array}$} & \multicolumn{2}{|c|}{$A_{380} / A_{330}$} \\
\hline & & & PAR-1† & PAR-2 $\ddagger$ & PAR-1 & PAR-2 \\
\hline \multirow[t]{2}{*}{ Red } & \multirow[t]{2}{*}{12} & $\overline{\mathbf{x}}$ & 355 & 483 & 0.50 & 1.28 \\
\hline & & $\mathrm{s}_{\overline{\mathbf{x}}}$ & 34 & 55 & 0.06 & 0.10 \\
\hline \multirow[t]{2}{*}{ Green } & \multirow[t]{2}{*}{9} & $\overline{\mathbf{x}}$ & 516 & 580 & 0.30 & 0.76 \\
\hline & & $s_{\overline{\mathbf{x}}}$ & 40 & 47 & 0.04 & 0.06 \\
\hline
\end{tabular}

+ PAR-1 indicates a radiation level of about $180 \mu \mathrm{E} \cdot \mathrm{m}^{-2} \cdot \mathrm{sec}^{-1}$. $\ddagger$ PAR-2 indicates a radiation level of about $400 \mu \mathrm{E} \cdot \mathrm{m}^{-2} \cdot \mathrm{sec}^{-1}$.

green-stemmed under PAR-1 developed some red color under PAR-2. This pigmentation was most intense in the seedling stem (i.e. the coleoptile and first leaf sheath), but red coloration also developed in the first leaf blades of some of the entries, especially on the abaxial surface. Accompanying these changes in stem coloration were changes in the ultraviolet absorption spectra of leaf extracts in alkaline solution. When grown under PAR-1, each of the 21 entries yielded a first-leaf extract having the $330 \mathrm{~nm}$ absorption maximum characteristic of $p-\mathrm{HB}$; and although all extracts had some absorption in the 350 to 400 region, only one had an absorption peak (near 380 $\mathrm{nm}$ ) in this region. However, when seedlings were grown under PAR-2, five of the 21 entries lacked the $330 \mathrm{~nm}$ peak, and each of the 21 had a peak near $380 \mathrm{~nm}$. Ratios of $A_{380}: A_{330}$ for PAR-2 were about 2.5 times as high as those for PAR-1 (Table 1).

The preliminary conclusions from this experiment were that substance(s) having an absorption maximum near $380 \mathrm{~nm}$ in alkali were present in relatively greater abundance in red-stemmed than in green-stemmed seedlings, and in seedlings grown under PAR-2 than in those grown under PAR-1. Also, it appeared that the substance(s) with the $380 \mathrm{~nm}$ peak might have interfered with HCN-p determinations based on $\mathrm{A}_{330}$ readings. Despite this probable interference, $\mathrm{HCN}$-p values for seedlings grown under PAR-1 and PAR-2 were highly correlated; $r=0.88^{* *}$ for 12 red-stemmed entries, $0.92^{* *}$ for nine green-stemmed entries, and $0.85^{* *}$ overall (**, significant at the 0.01 level).

Experiment 2. Seedlings of 11 entries, two of which (2406 and 1461) had been included in Exp. 1, were grown under PAR-1 and PAR-2. Six of the entries were sudangrasses, and five were forage sorghums. These entries covered a wider range in HCN-p (from about 200 to about 1300 ppm under PAR-1) than those in Exp. 1. When grown under PAR-2, each of the 11 entries had a higher apparent HCN-p than when grown under PAR-1 (Table 2). PAR-associated differences in the $A_{380}: A_{330}$ ratio were in the same direction but, on the average, were less pronounced than those observed in Exp. 1. This difference in response was probably related to the fact that in Exp. 2 most of the entries failed to display a 380 nm absorption peak under PAR-2, whereas in Exp. 1, all of the entries had such a peak. Under PAR-1, 6 of the 11 entries in Exp. 2 had green stem color; under PAR-2 only 3 entries, all forage sorghums, had green stems. Differences in $\mathrm{A}_{380}$ : $\mathrm{A}_{330}$ values between green and red-stemmed entries were less pronounced than those in Exp. 1. 
Table 2. Stem color, apparent $H C N-p, A_{s s o} / A_{3 s 0}$, and $A_{s s o}(e t h e r) / A_{s s o}(o r i g i n a l)$ for seedlings of six sudangrass and five forage sorghum entries grown under PAR-1 and PAR-2 (Exp. 2). Duplicate five-leaf samples were assayed for each entry.

\begin{tabular}{|c|c|c|c|c|c|c|c|c|}
\hline \multirow[b]{2}{*}{ Entry } & \multicolumn{2}{|c|}{ Stem color§ } & \multicolumn{2}{|c|}{ Apparent HCN-p (ppm) } & \multicolumn{2}{|c|}{$\mathbf{A}_{380} / \mathbf{A}_{330}$} & \multicolumn{2}{|c|}{$\mathbf{A}_{330}$ (ether)/A $\mathbf{A}_{330}$ (original) } \\
\hline & PAR-1† & PAR-2 + & PAR-1 & PAR-2 & PAR-1 & PAR-2 & PAR-1 & PAR-2 \\
\hline \multicolumn{9}{|c|}{ Sudangrass } \\
\hline $154-1$ & $\mathrm{G}$ & $\mathbf{R}$ & 229 & 314 & 0.70 & 1.39 & 0.53 & 0.28 \\
\hline $166-9$ & $\mathrm{G}$ & $\mathbf{R}-$ & 375 & 519 & 0.50 & 0.61 & 0.59 & 0.54 \\
\hline $240-6$ & G & $\mathrm{R}-$ & 524 & 560 & 0.33 & 0.63 & 0.66 & 0.58 \\
\hline $159-9$ & $\mathrm{R}$ & $\mathrm{R}++$ & 494 & 552 & 0.37 & 0.62 & 0.65 & 0.55 \\
\hline $219-3$ & $\mathbf{R}$ & $\ddot{R}++$ & 470 & 589 & 0.27 & 0.45 & 0.69 & 0.65 \\
\hline 1461 & $\mathrm{R}$ & $\mathbf{R}+$ & 210 & 307 & 0.82 & 1.55 & 0.52 & 0.23 \\
\hline$\overline{\mathbf{x}} \pm \mathrm{s}_{\overline{\mathbf{x}}}$ & & & $384 \pm 56$ & $474 \pm 52$ & $0.50 \pm 0.09$ & $0.88 \pm 0.19$ & $0.61 \pm 0.03$ & $0.47 \pm 0.07$ \\
\hline \multicolumn{9}{|c|}{ Forage sorghum } \\
\hline 1567 & $\mathrm{G}$ & G & 888 & 1183 & 0.14 & 0.17 & 0.76 & 0.77 \\
\hline 1603 & G & $\mathrm{G}$ & 897 & 959 & 0.23 & 0.32 & 0.76 & 0.70 \\
\hline 1615 & G & G & 1348 & 1822 & 0.14 & 0.17 & 0.78 & 0.76 \\
\hline 2132 & $\mathbf{R}$ & $R+$ & 734 & 780 & 0.20 & 0.32 & 0.76 & 0.67 \\
\hline 1601 & $\mathrm{R}$ & $\mathbf{R}++$ & 1209 & 1255 & 0.16 & 0.27 & 0.70 & 0.66 \\
\hline$\overline{\mathrm{x}} \pm \mathrm{s}_{\overline{\mathrm{x}}}$ & & & $1015 \pm 113$ & $1200 \pm 177$ & $0.17 \pm 0.02$ & $0.25 \pm 0.03$ & $0.75 \pm 0.01$ & $0.71 \pm 0.02$ \\
\hline
\end{tabular}

+ PAR-1 indicates a radiation level of about $180 \mu \mathrm{E} \cdot \mathrm{m}^{-2} \cdot \mathrm{sec}^{-1}$.

†AR-2 indicates a radiation level of about $400 \mu \mathrm{E} \cdot \mathrm{m}^{-2} \cdot \mathrm{sec}^{-1}$.

$\$ \mathrm{G}$ indicates green stems, $\mathrm{R}$ indicates red stems, - and + signs signify color intensity.

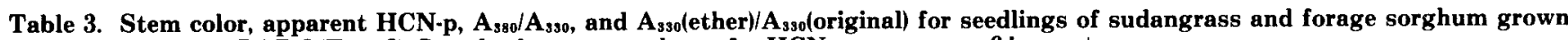
under PAR-1 and PAR-2 (Exp. 3). Standard errors are shown for HCN-p means; $n=6$ in most cases.

\begin{tabular}{|c|c|c|c|c|c|c|c|c|}
\hline \multirow[b]{2}{*}{ Entry } & \multicolumn{2}{|c|}{ Stem color $\S$} & \multicolumn{2}{|c|}{ Apparent HCN-p (ppm) } & \multicolumn{2}{|c|}{$A_{380} / A_{330}$} & \multicolumn{2}{|c|}{$\mathbf{A}_{330}$ (ether)/A $\mathbf{A}_{330}$ (original) } \\
\hline & PAR-1† & PAR-2 $\ddagger$ & PAR-1 & PAR-2 & PAR-1 & PAR-2 & PAR-1 & PAR-2 \\
\hline \multicolumn{9}{|c|}{ Sudangrass } \\
\hline $154-1$ & $\mathrm{G}$ & $\mathrm{R}-$ & $272 \pm 9$ & $325 \pm 11$ & 0.56 & 1.23 & 0.57 & 0.36 \\
\hline $155-3$ & G & $\mathrm{G}$ & $410 \pm 8$ & $452 \pm 17$ & 0.41 & 0.53 & 0.65 & 0.56 \\
\hline $154-6$ & $\mathrm{R}$ & $\mathrm{R}+$ & $311 \pm 6$ & $342 \pm 16$ & 0.53 & 1.14 & 0.56 & 0.37 \\
\hline 1461 & $\mathrm{R}$ & $\mathbf{R}+$ & $189 \pm 10$ & $269 \pm 14$ & 0.94 & 1.61 & 0.48 & 0.21 \\
\hline \multicolumn{9}{|c|}{ Forage sorghum } \\
\hline 1612 & $\mathrm{G}$ & $\mathbf{G}$ & $1254 \pm 20$ & $1449 \pm 44$ & 0.14 & 0.17 & 0.67 & 0.74 \\
\hline 1615 & $\mathrm{G}$ & $\mathrm{G}$ & $1004 \pm 15$ & $1400 \pm 67$ & 0.20 & 0.18 & 0.66 & 0.72 \\
\hline 1599 & $\mathbf{R}$ & $\mathbf{R}+$ & $1084 \pm 18$ & $1267 \pm 19$ & 0.11 & 0.16 & 0.69 & 0.72 \\
\hline 1598 & $\mathrm{R}$ & $\mathbf{R}+$ & $1128 \pm 43$ & $1168 \pm 11$ & 0.17 & 0.23 & 0.73 & 0.68 \\
\hline
\end{tabular}

+ PAR 1 indicates a radiation level of about $180 \mu \mathrm{E} \cdot \mathrm{m}^{-2} \cdot \mathrm{sec}^{-1}$.

$¥$ PAR-2 indicates a radiation level of about $400 \mu \mathrm{E} \cdot \mathrm{m}^{-2} \cdot \mathrm{sec}^{-1}$.

$\$ \mathrm{G}$ indicates green stems, $\mathbf{R}$ indicates red stems, - and + signs signify color intensity.

Portions of the extracts prepared in Exp. 2 were extracted with ether as described in Materials and Methods, and the resulting aqueous and reconstituted ether phases were diluted in base for spectral scanning between 400 and $250 \mathrm{~nm}$. Each reconstituted ether phase had a pronounced peak at $330 \mathrm{~nm}$ and none had a $380 \mathrm{~nm}$ peak; none of the aqueous phases had $330 \mathrm{~nm}$ peak, but a 380 nm peak was present in those aqueous phases that came from original extracts with a $380 \mathrm{~nm}$ peak. Thus, ether extraction effectively separated $p$-HB (absorption maximum at $330 \mathrm{~nm}$ ) from the material(s) responsible for the $380 \mathrm{~nm}$ peak. Calculation of mean $\mathrm{A}_{330}$ (ether)/ $\mathrm{A}_{330}$ (original) values for PAR-1 seedlings indicated that about $67 \%$ of the $A_{330}$ reading of the original extract was accounted for by the ether phase. A slightly lower mean value (58\%) was observed for seedlings grown under PAR-2. This lower mean resulted primarily from the low values (about $25 \%$ ) for the two low-HCN-p sudangrass entries, 154-1 and 1461 .

Experiment 3. Four sudangrass and four forage sorghum entries were grown in a randomized complete block design with three replications under PAR-1. The same experiment was conducted simultaneously under PAR-2. Two of the sudangrass entries and one forage sorghum that had been used in Exp. 2 were included in the eight entries of Exp. 3. Duplicate samples of five first leaves were taken from each entry within each replication; thus, most of the means in Table 3 are based on six observations. Because the light treatments were administered in separate growth chambers and chambers were not replicated, this experiment did not permit a statistically valid measure of possible differences due to light level. However, as in Exp. 1 and 2, seedling HCN-p values in this experiment were consistently higher under PAR-2 than under PAR-1. Also, as in Exp. 2, the $A_{380} / A_{330}$ ratios, in most cases, were higher under PAR-2, especially for the sudangrass entries; and the ether extraction ratios, $\mathrm{A}_{3,31}$ (ether)/A $\mathbf{A}_{330}$ (original), were lowest for the sudangrass entries that were lowest in HCN-p and grown under PAR2.

The three entries that were included in both Exp. 2 and 3 were 154-1, 1461, and 1615. Comparison of data for these entries in Tables 2 and 3 indicates that values for $\mathrm{HCN}-\mathrm{p}, \mathrm{A}_{330} / \mathrm{A}_{330}$, and $\mathrm{A}_{330}$ (ether) $/ \mathrm{A}_{330}$ (original) did not differ greatly between the two experiments.

Absorption spectra of original extracts, aqueous phases, and reconstituted ether phases for Entries 1461 (a lowHCN-p sudangrass) and 1599(a high-HCN-p forage sorghum cultivar, 'Rancher') are shown in Fig. 1. These spectra illustrate the efficacy of ether extraction for sepa- 
rating $p-\mathrm{HB}$ from other constituents, the lack of solubility of the $380 \mathrm{~nm}$-absorbing compound(s) in ether, and the large effect of PAR-2 upon the spectral characteristics of extracts from Entry 1461.

Correlations. Calculations of correlation coefficients (Table 4) revealed that in each experiment, $H C N$-p values for seedlings grown under PAR-1 were highly correlated with those for seedlings grown under PAR-2, despite the fact that in most instances higher HCN-p values were observed under PAR-2 than under PAR-1. The negative and generally high $\mathrm{r}$ values for the relationship between HCN-p and $\mathrm{A}_{380} / \mathrm{A}_{334}$ support the conclusion that $\mathrm{A}_{330^{-}}$ based HCN-p values for high-HCN-p entries were af-

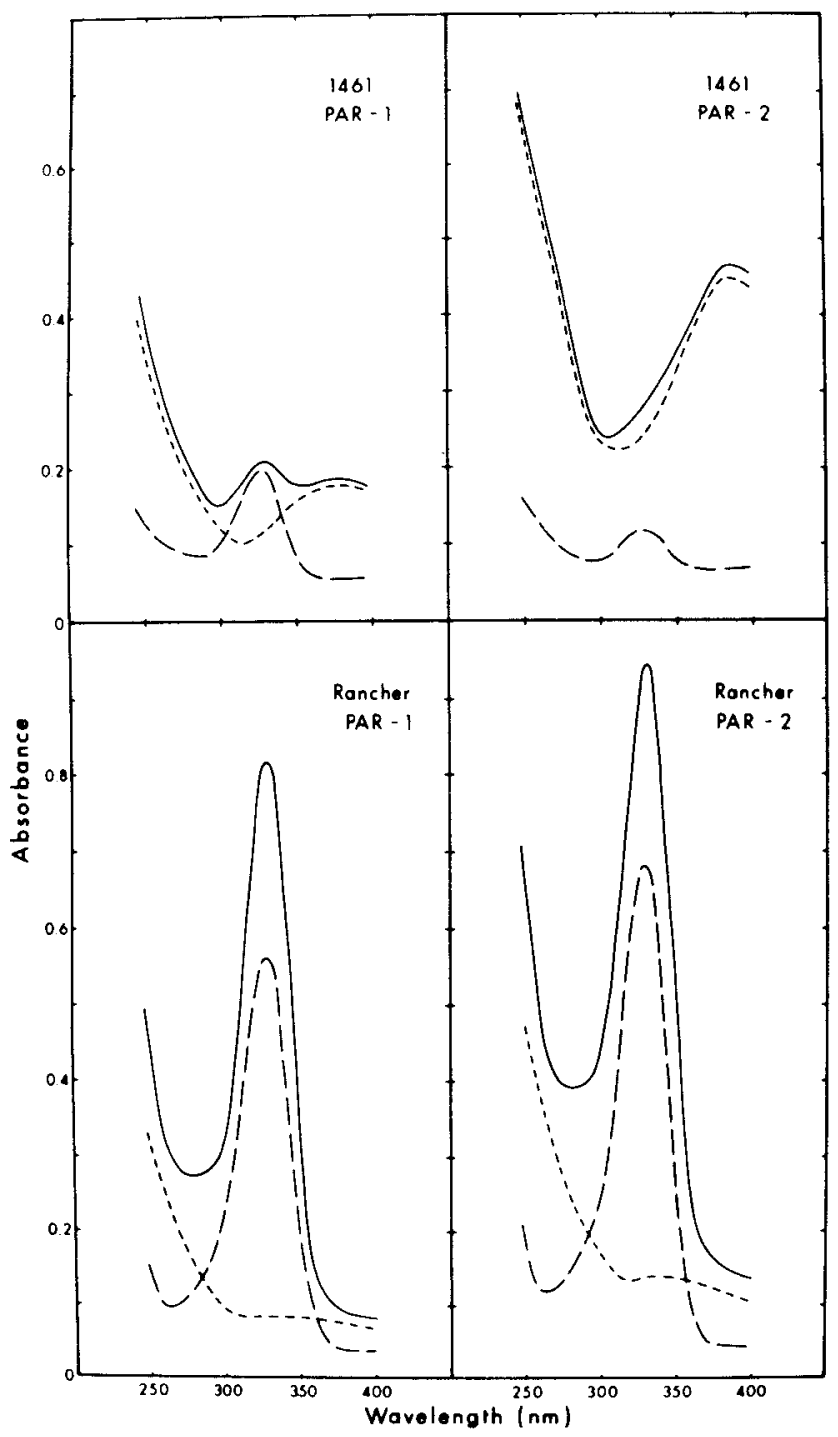

Fig. 1. Absorption spectra of original extracts (aqueous phases (--.-), and reconstituted ether phases (- ) derived from first leaves of Entry 1461 and Rancher (Entry 1599). Solvent: $0.1 \mathrm{~N} \mathrm{NaOH}$. Dilutions: $1: 6$ for all solutions. In reconstituting the ether phases, $10 \mathrm{ml}$ (the original volume) was used for Rancher, and $5 \mathrm{ml}$ for 1461. HCN-p values ( $\mathrm{ppm}$ ), based on $A_{330}$ readings of original extracts: Rancher - PAR-1, 1084 and PAR-2, 1267; 1461 - PAR-1, 189 and PAR-2, 269. fected less by extraneous $330 \mathrm{~nm}$-absorbing compounds than were the values for low HCN-p entries. The positive relationship between $H C N-p$ and the fraction of $330 \mathrm{~nm}$ absorbance attributable to ether-extractable compounds was similarly close. Highest correlation coefficients were observed for the negative relationship between the $A_{380}$ l $\mathrm{A}_{330}$ and the $\mathrm{A}_{331)}$ (ether)/ $\mathrm{A}_{330}$ (original) ratios.

Correction of $H C N-p$ Values. The $\mathrm{A}_{330}$ (ether)/ $\mathrm{A}_{330}$ (original) ratios shown in Tables 2 and 3 indicate that the ether phases accounted for no more than about $75 \%$ of the absorbance of the original extracts at $330 \mathrm{~nm}$. The remaining $25 \%$ or more of this absorbance was attributed to the respective aqueous phases which had appreciable absorbance at $330 \mathrm{~nm}$ but lacked maxima at this wavelength. To investigate the possibility that this absorbance might be due primarily to $p$-HB remaining in the aqueous phase, the following experiment was done. Seven-day seedlings of Entries 1461 and 1599 were grown under PAR-1 and PAR-2, and extracts of first leaves were prepared in the usual way. A $p$-HB solution was added to one portion of each extract such that the final concentration of added $p$-HB was $12 \mu \mathrm{g} / \mathrm{ml}$. Portions of extracts with and without this added $p$ - $\mathrm{HB}$ were then extracted with ether as described in Materials and Methods. Samples were then diluted in $0.1 \mathrm{~N} \mathrm{NaOH}$, and spectra were scanned. Calculations of recovery of the added $p-\mathrm{HB}$ in the ether phase were based on $\mathrm{A}_{330}$ readings. Recovery percentages were 91 and 86 for Entry 1461, and 96 and 100 for Entry 1599 (in each case the first value refers to PAR-1 and the second to PAR-2). The recovery of $p-\mathrm{HB}$ extracted from a water solution was $89 \%$. In view of these results it may be concluded that about $90 \%$ of the $p-\mathrm{HB}$ present in the leaf extracts was removed by ether extrac-

Table 4. Correlation coefficients for various comparisons in Experiments 1 through 3.

\begin{tabular}{|c|c|c|c|c|}
\hline Comparison & $\begin{array}{c}\text { Experi- } \\
\text { ment }\end{array}$ & $\begin{array}{l}\text { Radiation } \\
\text { level }\end{array}$ & $\mathbf{n}$ & $\mathbf{r}$ \\
\hline \multicolumn{5}{|l|}{ Apparent HCN-p, PAR-1† } \\
\hline \multirow[t]{3}{*}{ vs. PAR- $2 \ddagger$} & 1 & & 21 & $0.85^{* * *}$ \\
\hline & 2 & & 11 & $0.97 * *$ \\
\hline & 3 & & 8 & $0.98 * *$ \\
\hline \multirow{9}{*}{ Apparent $H C N-p$ vs. $A_{380} / A_{330}$} & 1 & PAR-1 & 21 & $-0.86^{* *}$ \\
\hline & & PAR-2 & 21 & $-0.70^{* *}$ \\
\hline & & Both & 42 & -0.25 \\
\hline & 2 & PAR-1 & 11 & $-0.83^{* *}$ \\
\hline & & PAR-2 & 11 & $-0.75^{* *}$ \\
\hline & & Both & 22 & $-0.65 * *$ \\
\hline & 3 & PAR-1 & 8 & $-0.90^{* *}$ \\
\hline & & PAR-2 & 8 & $-0.90^{* *}$ \\
\hline & & Both & 16 & $-0.78^{* *}$ \\
\hline \multicolumn{5}{|l|}{ Apparent HCN-p vs. } \\
\hline \multirow[t]{6}{*}{$\mathrm{A}_{330}$ (ether)/ $\mathrm{A}_{330}$ (original) } & 2 & PAR-1 & 11 & $0.83^{* *}$ \\
\hline & & PAR-2 & 11 & $0.77^{* *}$ \\
\hline & & Both & 22 & $0.67 * *$ \\
\hline & 3 & PAR-1 & 8 & $0.86^{* *}$ \\
\hline & & PAR-2 & 8 & $0.93^{* *}$ \\
\hline & & Both & 16 & $0.79^{* *}$ \\
\hline \multirow{7}{*}{$\begin{array}{l}A_{980} / A_{330} \text { vs. } \\
A_{330}(\text { ether }) / A_{330} \text { (original) }\end{array}$} & & & & \\
\hline & 2 & PAR-1 & 11 & $-0.95 * *$ \\
\hline & & PAR-2 & 11 & $-0.99 * *$ \\
\hline & & Both & 22 & $-0.99 * *$ \\
\hline & 3 & PAR-1 & 8 & $-0.95^{* *}$ \\
\hline & & PAR-2 & 8 & $-0.99 * *$ \\
\hline & & Both & 16 & $-0.99 * *$ \\
\hline
\end{tabular}

** Indicates significance at the 0.01 level of probability.

+PAR-1 indicates a radiation level of about $180 \mu \mathrm{E} \cdot \mathrm{m}^{-2} \cdot \mathrm{sec}^{-1}$.

$\ddagger$ PAR-2 indicates a radiation level of about $400 \mu \mathrm{E} \cdot \mathrm{m}^{-2} \cdot \mathrm{sec}^{-1}$. 
tion. The high efficiency of the ether extraction and the shapes of the absorbance spectra of aqueous phases (Fig. 1) rule out the possibility that $p$ - $\mathrm{HB}$ contributed in a major way to the $A_{330}$ values of the aqueous phases.

The recovery fraction $(0.9)$ was used to calculate corrected $H C N-p$ values for each entry and light treatment in Exp. 2 and 3 by the following equation:

Corrected HCN-p

$=\left[\right.$ original HCN-p $\times \mathrm{A}_{330}($ ether $) / \mathrm{A}_{330}$ (original) $] / 0.9$

Calculations were then made of the ratio of HCN-p under PAR-2 to that under PAR-1 for both the original and corrected $H C N-p$ values. Mean $( \pm S E)$ ratios for the combined entries of Exp. 2 and 3 (Tables 2 and 3 ) were as follows: Original - sudangrass, $1.25 \pm 0.05$; forage sorghum, $1.18 \pm 0.05$. Corrected - sudangrass, $0.88 \pm$ 0.07 ; forage sorghum, $1.17 \pm 0.07$. In other words, the mean HCN-p of the forage sorghums was about $118 \%$ as high under PAR-2 as under PAR-1, based on either the original or corrected values. For the sudangrass entries, however, original values indicated that HCN-p under PAR-2 was about $125 \%$ of that under PAR-1, but corrected values showed that HCN-p under PAR-2 was only $88 \%$ as high as that under PAR-1. Most extreme differences between original and corrected PAR-2/PAR-1 ratios were noted for the low-HCN-p entries 154-1 and 1461. For 154-1, original and corrected ratios (mean of Exp. 2 and 3 ) were, respectively, 1.28 and 0.74 ; for 1461 the ratios were 1.44 and 0.63 . Seedlings of both $154-1$ and 1461 formed more red pigment under PAR-2 than under PAR-1, but this was also true of several high-HCN-p entries. The possibility is suggested that utilization of the seedling's metabolic resources for the formation of red pigment was effective in reducing the extent of dhurrin synthesis only in those seedlings where the level of this synthesis already was relatively low.

Extraction of Tillers. The absorption spectrum of a firstleaf extract from the PAR-2-grown low-HCN-p line, Entry 1461 (Fig. 1), was very similar to that of a tiller extract from field-grown, low-HCN-p 'Piper' sudangrass (5). In the earlier experiment with tillers of Piper and other entries, no attempt was made to fractionate the aqueous tiller extracts with ether. Fractionation with ether was done, however, in the summer of 1979. Tillers were harvested from 15 sudangrass plants established from transplanted seedlings that had been grown under PAR-1 and assayed for HCN-p at 7 days. Five of the plants (the low group) came from seedlings with a mean ( \pm SE) HCN-p of 167 $\pm 8 \mathrm{ppm}$; five (the intermediate group) from seedlings with $250 \pm 7 \mathrm{ppm}$; and five (the high group) from seedlings with $370 \pm 15 \mathrm{ppm}$. One tiller about $20 \mathrm{~cm}$ tall was harvested from each plant, and the oldest leaf without a collar was excised for extraction and assay. Based on $\mathrm{A}_{330}$ readings, the $H C N$-p values for the three groups of tillers were: low $-99 \pm 10$; intermediate $-154 \pm 20$; and high $-191 \pm 16$. The correlation for seedling vs. tiller HCN$\mathbf{p}(\mathbf{n}=15)$ was $0.75^{* *}$, which is similar to previously observed values for this relationship (5). At least as interesting as the relationship between seedling and tiller HCN-p values is the observation that spectra of ether extracts de- rived from tillers of each of the five low-HCN-p entries revealed either no peak or only slight peaks at about $330 \mathrm{~nm}$. Peaks at $330 \mathrm{~nm}$ were readily apparent in spectra of ether extracts representing each of the intermediate and high$\mathrm{HCN}$-p sudangrass entries. Mean $\mathrm{A}_{330}$ (ether)/ $\mathrm{A}_{330}$ (original) values for the tiller extracts were $0.18 \pm 0.02,0.39$ $\pm 0.05,0.44 \pm 0.04$ for the low, intermediate, and high groups, respectively. the very low $\mathrm{A}_{330}$ (ether)/ $\mathrm{A}_{330}$ (original) values, plus the lack of well defined $330 \mathrm{~nm}$ peaks in the ether extracts from the low group, indicate that the tillers of these plants were indeed very low in HCN-p and that the spectrophotometric assay of seedlings grown under PAR-1 was an effective selection method.

General Discussion and Conclusions. The experiments of Downs and Siegelman (3) and Stafford (7) demonstrated the pronounced influence of light on the development of anthocyanins in etiolated sorghum seedlings. Also, Stafford (8) identified the principal flavonoid in green leaves from young plants of 'Wheatland' sorghum as luteolin-7glucoside. These compounds, as well as many other related phenolic substances, absorb strongly in the ultraviolet range. It would not be surprising if the substances responsible for the interfering ultraviolet absorption in the present study were found to be phenolics, but as yet the compounds have not been identified.

Whatever the nature of the compounds responsible for this interference, it is clear that the interference can be a serious problem in a program of selection for low $\mathrm{HCN}$ $p$, especially if the seedlings are grown under relatively high light levels. Therefore, we recommend that seedlings to be used in the spectrophotometric assay be grown under PAR levels of 150 to $200 \mu \mathrm{E} \cdot \mathrm{m}^{-2} \cdot \mathrm{sec}^{-1}$, and that any entry assaying less than 250 ppm HCN-p by this method be further examined by scanning the specirum of its leaf extracts from 400 to $250 \mathrm{~nm}$ and possibly by fractionation of the leaf extracts with ether.

\section{ACKNOWLEDGMENT}

The excelient technical assistance of Susan Versaw, Jeffrey Arnold. and Paul Pier is gratefully acknowledged.

\section{REFERENCES}

1. Akazawa, T., P. Miljanich, and E. E. Conn. 1960. Studies on cyanogenic glycoside of Sorghum vulgare. Plant Physiol. 35:535-538.

2. Clark, R. B., H. J. Gorz, and F. A. Haskins. 1979. Effects of mineral elements on hydrocyanic acid potential in sorghum seedlings. Crop Sci. 19:757-761

3. Downs, R. J., and H. W. Siegelman. 1963. Photocontrol of anthocyanin synthesis in milo seedlings. Plant Physiol. 38:25-30

4. Gorz, H. J., W. I. Haag, J. E. Specht, and F. A. Haskins. 1977 Assay of $p$-hydroxybenzaldehyde as a measure of hydrocyanic acid potential in sorghums. Grop Sci. 17:578-582.

5. Haskins, F. A., H. J. Gorz, and R. L. Nielsen. 1979. Comparison of the hydrocyanic acid potential of Sorghum seedlings and tillers. Agron. J. 71:501-504

6. Hoagland, D. R., and D. I. Arnon. 1950. The water-culture method for growing plants without soil Calif. Agric. Exp. Stn. Circ. 347, revised.

7. Stafford, H. A. 1965. Flavonoids and related phenolic compounds produced in the first internode. of Sorghum uulgare Pers. in darkness and in light. Plant Physiol. 40:130-138.

8. --. 1969. Changes in phenolic compounds and related enzymes in young plants of sorghum. Phytochemisty $8: 743-752$. 